Revista lus et Praxis, Año 21, No 1, 2015, pp. 345 - 376

ISSN 0717 - 2877

Universidad de Talca - Facultad de Ciencias Jurídicas y Sociales

"El principio non bis in idem en el derecho disciplinario del abogado, en Colombia"

María Lourdes Ramírez Torrado

Paola Álvarez

Trabajo recibido el 13 de agosto de 2014 y aprobado el 21 de enero de 2015

\title{
El principio non bis in idem en \\ el derecho disciplinario del abogado, en Colombia*
}

THE NON BIS IN IDEM PRINCIPLE IN LAWYERS DISCIPLINARY LAW, IN COLOMBIA

\author{
María Lourdes Ramírez Torrado** \\ PaOla Álvarez ${ }^{* * *}$
}

Resumen

El ejercicio de la abogacía en Colombia se encuentra regulado por la ley No 1123/2007, norma que contempla: los deberes, incompatibilidades, las conductas calificadas como faltas, las sanciones y procedimientos de la actividad de los profesionales del derecho. Sin embargo, al igual que ocurre en otros campos de la actividad administrativa sancionadora, ni en esa ley como tampoco en otras se regulan las implicaciones del principio non bis in idem, dejando lagunas que en ocasiones han sido Ilenadas por la Corte Constitucional y en otras por el Consejo de Estado, pero que en todo caso, debieron ser objeto de desarrollo por parte del legislador, pues el sujeto disciplinable se encuentra, en cada caso, al vaivén de las interpretaciones, amplias o restrictivas del intérprete de turno.

ABSTRACT

The practice of law in Colombia is regulated by the law 1123/2007, which provides the duties, incompatibilities, conduct classified as misdemeanors, penalties and the procedures for the practice of the professional activity. However, as happens in other fields of administrative sanctions activities, neither this law nor any other law regulates the implications of the non bis in idem principle; sometimes leaving gaps that have been filled up by the Constitutional Court or the Council of State. Nonetheless, they should have been further developed by the legislature, as the disciplinable subject is in each case depending on the sway of interpretations made by the legislator in turn.

\section{Palabras Clave}

Derecho administrativo sancionador, Sanción administrativa, Derecho disciplinario

\section{KEYWORDS}

Sanctioning administrative law, Administrative sanctions, Disciplinary law

\footnotetext{
* Este artículo es resultado de una investigación, que se enmarca en el proyecto titulado: "Potestad sancionadora de la Administración en Colombia".

** Profesora investigadora de la División de Ciencias Jurídicas de la Universidad del Norte (Barranquilla, Colombia). Doctora en Derecho administrativo. Magíster en Derecho. Correo electrónico: torradom@ uninorte.edu.co.

*** Magíster en Derecho, Juez primera del circuito de Corozal. Correo electrónico: paralme1 @hotmail.com.
} 


\section{Introducción}

Históricamente se ha reconocido al Estado la facultad de imponer sanciones a quien infringe sus normas. Así, lo que en principio se denominó: "derecho a castigar", posteriormente adoptó la forma de potestad sancionadora reglada que, bajo la denominación de ius puniendi, comprende actualmente cinco especies, a saber: derecho penal, derecho contravencional, derecho correccional, derecho de punición por indignidad política y derecho disciplinario.

Dentro de ese panorama, se ha expresado que si bien el poder es único e indivisible, las circunstancias exigen que la administración de justicia no sea una función exclusiva de la rama judicial, de manera tal que se ha conferido a la administración pública potestad sancionadora, surgiendo así el área del derecho que se conoce como: Derecho Administrativo Sancionador ${ }^{1}$.

Al interior del ius puniendi aparece el derecho disciplinario, el cual se ha erigido también como rama autónoma e independiente, buscando regular las relaciones del Estado con sus funcionarios y con los particulares que le colaboran en la consecución de sus fines. Así, se desarrolla dentro del marco de las relaciones de sujeción especial, en las cuales los individuos tienen unas cargas superiores a las del común de las personas.

Pues bien, dado que la abogacía cumple una función social que la convierte en una profesión de servicio a la comunidad, quienes la ejercen poseen con el Estado ese vínculo especial que los hace merecedores de un tratamiento legal más exigente, de manera tal que el abogado está sometido a la disciplina propia del servidor público, al punto que su disciplinamiento ha sido asignado a un órgano especial de carácter judicial, Consejo Superior de la Judicatura.

Esta actuación disciplinaria, al igual que toda actuación administrativa o judicial, debe ceñirse al debido proceso, establecido como derecho fundamental en el artículo 29 constitucional. Así, los abogados cuya situación haya sido resuelta mediante sentencia ejecutoriada o decisión que tenga la misma fuerza vinculante proferida por autoridad competente, no podrán ser sometidos a una nueva investigación y juzgamiento disciplinario por el mismo hecho aun cuando a éste se le dé una denominación jurídica distinta. Sin embargo, el desarrollo legal del non bis in idem en torno al derecho disciplinario abogadil es escaso, de manera tal que no existe ninguna otra norma que lo regule o precise su alcance.

Entonces, se acepta de manera pacífica que un abogado no puede ser sancionado dos veces por el mismo hecho, igualmente que no puede ser objeto

1 Al respecto la obra de OsSa Arbeláez (2000). 
de dos procesos distintos, pero no existe una misma línea en la doctrina, en el caso cuanto al hecho que un abogado por tener también la calidad de servidor público, pueda más de una autoridad ser competente para disciplinarlo; o cuando por la utilización de tipos en blanco y de descripción imprecisa y similar se encuadra un mismo comportamiento en distintas faltas disciplinarias. Estos aspectos y otros, tales como: el manejo de la conexidad; las infracciones mediales, los concursos ${ }^{2}$, llevan a cuestionarse si la normatividad vigente en materia abogadil permite que se quebrante el principio del non bis in idem.

Así las cosas, el objetivo de estas páginas es determinar el alcance del principio non bis in idem en el sector del derecho abogadil, y para ello se realiza un estudio que se basa principalmente en la revisión de bibliografía, las leyes y la jurisprudencia sobre la materia, proponiéndose una visión distinta del tema investigado.

\section{El derecho a no ser sancionado dos veces: principio non bis in idem ${ }^{3}$}

El principio non bis in idem tiene su origen en el derecho romano, estando los efectos del postulado restringidos a la esfera procesal del mismo. Según afirma Nisimblat ${ }^{4}$ el non bis in idem proviene de la institución de derecho romano conocida como "Res iudicata pro veritate habetur", según la cual la cosa juzgada se considera como verdad. Manifiesta el autor, en cita, que la institución comentada surgió en el siglo II de la era cristiana en principio aplicable por vía directa sólo respecto de los pronunciamientos de un determinado tribunal (el judicium legitimum) y por vía de excepción para lo decidido por el judicium imperio continens y fue evolucionando al punto que en el siglo sexto aparece consagrada en el Corpus luris Civilis de Justiniano, el cual expresamente decía que quien había sido objeto de acusación por un crimen público no podía volver a serlo por el mismo hecho (Libro IX Título II número 9).

Posteriormente, el principio se fue imponiendo en los diversos sistemas de origen latino, de donde pasó al derecho español, específicamente en la ley de las Siete Partidas de Alfonso X (estableciendo la imposibilidad de reabrir un nuevo pleito en los casos en que éste fuese acabado y no se recurriese en alzada, o cuando uno era vencido por alguna cosa en juicio).

\footnotetext{
2 En relación con ello se pronuncia Romero Rodríguez (2013), pp. 213-219.

${ }^{3}$ En el estudio de este postulado del derecho administrativo sancionador en el contexto español, se encuentra el trabajo de RAmírez TORRADO (2010), pp. 287-302.

${ }^{4}$ Nisimblat (2009), p. 247.
} 
De sus remotos orígenes en el derecho romano, la prohibición fue adoptada por otros ordenamientos ${ }^{5}$, así los sistemas normativos realizaron una interpretación del principio, pero siempre respetando su sentido genuino como lo era: la prohibición que por un mismo hecho se abrieran dos expedientes a una misma persona 6 .

Trasladándonos al escenario nacional actual, es evidente como la máxima en estudio tiene plena vigencia, y para ello se ha ajustado a las circunstancias y exigencias de nuestro tiempo. De este modo, el principio no tiene una aplicación reducida al derecho penal ${ }^{7}$, sino que, por el contrario, tiene plena operatividad ahí donde se ejerza el ius puniendi del Estado. De esta forma, el derecho fundamental a no ser juzgado dos veces por un mismo hecho y bien jurídico cobra plena vigencia cuando el ius puniendi del Estado sea desplegado efectivamente por: los jueces, la administración pública, y por los particulares, en el ejercicio de funciones públicas, en la medida en que conforma los postulados que presiden el debido proceso sancionador ${ }^{8}$.

\footnotetext{
${ }^{5}$ El Principio bajo estudio ha sido consagrado en diversos instrumentos internacionales. Así, en el Protocolo número 7 al Convenio Europeo de Derechos Humanos, firmado el veintiocho de abril de 1983, en su artículo cuarto, consagró el derecho a no ser juzgado dos veces por los tribunales de un mismo Estado por una infracción por la que haya sido absuelto o condenado mediante sentencia firme conforme a la ley y al procedimiento de ese Estado.
}

Igualmente, el principio en comento aparece consagrado expresamente en el Pacto Internacional de Derechos Civiles y Políticos de la Convención Americana de Derechos Humanos o Pacto de San José (el artículo $8^{\circ}$ inciso $4^{\circ}$ enuncia "El inculpado absuelto por sentencia firme no podrá ser sometido a nuevo juicio por los mismos hechos"), el cual tiene fuerza vinculante para nuestro ordenamiento jurídico.

En desarrollo de esta norma, la Corte Interamericana de Derechos Humanos, en el caso Loayza Tamayo, mediante sentencia contenciosa de fecha 17 de septiembre de 1997, aseguró que: "este principio busca proteger los derechos de los individuos que han sido procesados por determinados hechos para que no vuelvan a ser enjuiciados por los mismos hechos".

Ahora bien, en el campo específico del derecho disciplinario no se ha encontrado ningún pronunciamiento de la Corte Interamericana sobre el principio de non bis in idem, siendo destacable, sólo, en lo que a las relaciones de sujeción especial respecta, el caso La Canuta Vs. Perú, en el que se procesó a militares por la justicia penal militar y sin embargo no fue validado el principio del non bis in idem por cuanto el proceso no había sido instruido de modo independiente o imparcial.

${ }^{6}$ López Barja De Quiroga (2004), p. 14.

En el año 1787 se realizó la quinta enmienda de la Constitución de los Estados Unidos, consagrándose como garantía que la vida o la integridad de una persona no podrá ser puesta en peligro dos veces por el mismo delito. Esta norma trasmite la idea de que una persona se encuentra en riesgo cuando se le juzga por un crimen y lo ampara de un doble procesamiento.

7 Huergo lora (2007), p. 436.

${ }^{8}$ Corte Constitucional de Colombia, sentencias al respecto: T-520/1993; C-092/1997; C-870/2002; T-1110/2005; C-11/2010; C-478/2007. 
La finalidad que busca el principio es la seguridad y certeza ${ }^{9}$, no solo del administrado, sino del sistema jurídico en su conjunto ${ }^{10}$, que el hecho por el cual ha sido sancionado o procesado, no sea revisado de nuevo por el Estado ${ }^{11}$, en dos, o incluso, en más ocasiones, en el mismo proceso o en otro futuro (T652/1996), y dentro de una misma jurisdicción.

\subsection{Consagración constitucional}

El Constituyente de 1991 visualizó un Estado sometido al derecho y, por ello, reconoció el debido proceso, aplicable a toda actuación judicial y administrativa, como derecho fundamental (artículo 29). Pues bien, entre las prerrogativas propias del derecho en comento, se consagró lo que universalmente ha sido denominado como: Principio del non bis in idem. "Quien sea sindicado tiene derecho (...) a no ser juzgado dos veces por el mismo hecho" dice expresamente nuestra Constitución (artículo 29), lo que implica no sólo la prohibición de doble sanción, sino también de doble procesamiento, en pro de la seguridad jurídica $^{12}$, de manera tal que en cualquier momento procesal se puede invocar esta máxima, si está demostrado que se reúnen los requisitos de ley.

Para que ello fuera posible se suscitaron varios debates al interior de la Asamblea Nacional Constituyente. De hecho, si bien en la sesión del 15 de junio de 1991 se aprobó el artículo 29 constitucional tal como hoy lo conoce$\operatorname{mos}^{13}$, en el primer proyecto presentado al respecto (cuyo autor fue el Gobierno Nacional), se manifestaba que todo acusado tiene derecho a no ser juzgado dos veces por la misma causa ${ }^{14}$. Posteriormente los constituyentes Juan Gómez Martínez y Hernando Londoño presentaron un nuevo proyecto, el cual, si bien desarrollaba el debido proceso, no contenía alusión alguna a la posibilidad de doble juzgamiento. Lo mismo ocurrió con el proyecto que posteriormente presentara Alfredo Vásquez Carrizosa ${ }^{15}$.

Ahora bien, ya en el acto reformatorio 050, entre cuyos autores está Antonio Navarro $^{16}$, aparece como garantía procesal el no poder ser procesado penal-

\footnotetext{
${ }^{9}$ Corte Constitucional de Colombia, sentencia al respecto: C-664/2007.

${ }^{10}$ Corte Constitucional de Colombia, sentencias al respecto: T-1216/2005; T-971/2008.

11 León De Villalba (1998), p. 447.

12 Corte Constitucional de Colombia, sentencia al respecto: sentencia C-214 de 1994.

13 Gaceta Constitucional número 109, del 15 de junio de 1991.

${ }^{14}$ Gaceta Constitucional número 5, del 15 de febrero de 1991.

15 Gaceta Constitucional número 12, del 20 de febrero de 1991.

${ }^{16}$ Gaceta Constitucional 22, del 18 de marzo de 1991.
} 
mente dos veces por el mismo hecho. Así mismo se aclara en un parágrafo que las garantías fundamentales constitucionales prescritas serían aplicables en lo pertinente a todo tipo de procesos.

Posteriormente fueron presentados otros proyectos de actos reformatorios. En uno cuyo autor fue Guillermo Plazas Alcid, se expresa que toda persona a la que se imputa un hecho punible tiene derecho a no ser sometida a un nuevo proceso por el mismo hecho, aun cuando a éste se le dé una denominación distinta, con excepción de lo previsto para el recurso extraordinario de revisión, la sentencia proferida en el exterior tendrá el valor de cosa juzgada en Colombia, salvo excepciones legales ${ }^{17}$. En otro ${ }^{18}$ se propone que: "toda persona acusada de un delito tiene derecho a no ser juzgada dos veces por la misma causa".

Por lo demás, debe destacarse que al aprobarse en primer debate por la subcomisión a la que le correspondía su estudio el artículo correspondiente al debido proceso, no se incluyó alusión alguna al non bis in idem, lo que mereció aclaración del constituyente Pastrana Borrero ${ }^{19}$. Igualmente Augusto Ramírez Ocampo hizo una propuesta al respecto, lográndose así que el 19 de abril se aprobara por unanimidad el artículo que incluía el principio en cita ${ }^{20}$, el cual, el 16 de mayo siguiente, fue incluido también en una norma que consagraba el derecho de defensa, pero con una variación relevante en cuanto a redacción y contenido. Existía el derecho a no ser juzgado dos veces por el mismo hecho, aun cuando a éste se le dé una denominación distinta.

Luego, los días $25^{21}$ y $27^{22}$ de mayo, se regresó al derecho a no ser juzgado dos veces por la misma causa, aunque al mismo tiempo ${ }^{23}$ la Sección Cuarta aprobó como principio de la administración de justicia que dentro del derecho penal se garantizaría el derecho de defensa que implica el derecho a no ser juzgado dos veces por el mismo hecho.

Importante es destacar que el constituyente Hernando Londoño Jiménez rindió un informe sobre: "Aplicación de los principios fundamentales del derecho penal en toda actividad punitiva del estado" 24 , en el cual destaca que el carácter del órgano que impone la sanción no altera la naturaleza del acto

17 Gaceta Constitucional 22, del 17 de abril de 1991.

18 Gaceta Constitucional 23, del 18 de abril de 1991.

19 Gaceta Constitucional 22, del 17 de abril de 1991.

${ }^{20}$ Gaceta Constitucional 24 del 19 de abril de 1991.

${ }^{21}$ Gaceta Constitucional 82, del 25 de mayo de 1991.

${ }^{22}$ Gaceta Constitucional 83, del 27 de mayo de 1991.

${ }^{23}$ Gaceta Constitucional 83, del 27 de mayo de 1991.

${ }^{24}$ Gaceta Constitucional 84, del 28 de mayo de 1991. 
punitivo, pues ninguna diferencia ontológica se aprecia entre sanciones administrativas y jurisdiccionales, comoquiera que unas y otras afectan intereses esenciales de la persona.

Por lo demás, en el informe comentado el constituyente Londoño Jiménez recordó la providencia de la Corte Suprema de Justicia del 7 de marzo de 1985, en la que con ponencia de Manuel Gaona Cruz, dicha Corporación destacó que el derecho punitivo es una disciplina de orden jurídico que absorbe como género cinco especies a las cuales son aplicables las garantías señaladas en la Constitución y en la legislación penal sustantiva y procesal que la desarrolle.

Entre esas garantías, obviamente se encuentra la de non bis in idem, con la claridad, hecha en esa oportunidad por la colegiatura señalada, que no por la misma conducta, sino en relación con esta, con prohibición de doble sanción por la misma especie punible.

\subsection{Consagración legal}

Diferentes estatutos procesales vigentes en Colombia consagran de manera expresa el principio a que se ha venido haciendo referencia, aun cuando dándole distintas denominaciones que por supuesto han de tener alcance diferente al momento de su aplicación.

Así, la ley No 906 de 2004 (Código de Procedimiento Penal), señala en su artículo 21 la cosa juzgada como principio rector del procedimiento penal y en virtud de éste aquella persona cuya situación jurídica hubiere sido definida mediante sentencia ejecutoriada o cualquiera otra providencia con la misma fuerza vinculante, no podrá ser nuevamente juzgada o sometida a investigación por los mismos hechos.

La norma en comento consagra como excepción que se trate de decisión obtenida con fraude o violencia; pronunciada en casos de violaciones a los derechos humanos o infracciones graves al Derecho Internacional Humanitario o que se establezcan mediante decisión de una instancia internacional de supervisión y control de derechos humanos, respecto de la cual el Estado colombiano ha aceptado formalmente la competencia.

Por su parte la ley № 734 de 2002 (Código Disciplinario Único), lo consagra como principio de ejecutoriedad en virtud del cual al destinatario de la acción disciplinaria no se le puede someter a doble investigación y juzgamiento por unos mismos hechos, aun cuando se denominen de manera diferente, excepto para el caso de los fallos sancionatorios, en el que procede la revocatoria directa, figura que puede servir como compuerta para que la corrupción pague favores políticos ${ }^{25}$.

25 Bula Romero (2006), p. 43. 
También se plantea que la revocatoria puede ser útil para combatir la impunidad, no obstante, la norma original contenida en la ley $N^{\circ} 734$ fue clara en cuanto a que sólo era aplicable para el caso de fallos sancionatorios y fue sólo a partir de la sentencia de la Corte Constitucional, C-014 de 2004, que se extendió a los fallos absolutorios y a la providencia de archivo de la actuación para los casos de faltas disciplinarias que constituyeran violaciones del derecho internacional de los derechos humanos y del derecho internacional humanitario.

Por lo demás, la ley № 1474 de 2011 decidió modificar el artículo 122 de la ley $\mathrm{N}^{\circ} 734$, incluyendo también como susceptibles de revocatoria directa los autos de archivo e incluso los fallos absolutorios ${ }^{26}$, cuando infrinjan manifiestamente las normas constitucionales, legales o reglamentarias en que deban fundarse o con ellos se vulneren o amenacen manifiestamente derechos fundamentales (artículo 49).

Para el caso específico de los abogados, la ley № 1123 de 2007, constitutiva del Código Disciplinario, consagra entre los principios rectores el non bis in idem (artículo 9०), en virtud del cual, aquellos profesionales del derecho que desempeñen funciones públicas relacionadas al ejercicio abogadil; en ejercicio de su profesión cumplan con la misión de asesorar, patrocinar y asistir a las personas naturales o jurídicas, tanto de derecho privado como de derecho público, en la ordenación y desenvolvimiento de sus relaciones jurídicas así se encuentren excluidos o suspendidos; actúen con licencia provisional; actúen como curadores ad litem o en representación de una firma o asociación de abogados suscriban contratos de prestación de servicios profesionales a cualquier título (artículo 19), cuya situación disciplinaria se haya resuelto mediante decisión ejecutoriada, Ilámese sentencia o auto de archivo, no podrán ser sometidos a nueva investigación o juzgamiento por unos mismos hechos.

Sin embargo, en ninguna de las normas en cita, se realiza un desarrollo del postulado.

\section{Estructura del principio non bis in idem}

La finalidad del principio de evitar la duplicidad de castigos (o procedimientos) por una misma actividad determina que tales requisitos estén relacionados con los siguientes aspectos: $1^{\text {a }}$ ) El principio opera en el ejercicio del ius puniendi estatal, lo que significa que la medida, aunque sea desfavorable, debe ser de

${ }^{26}$ Estos últimos, al tenor de lo dispuesto en el parágrafo del artículo 47 de la nueva ley, revocables sólo por el Procurador General de la Nación, de oficio o a petición del quejoso que tenga la calidad de víctima o perjudicado, cuando se trate de faltas disciplinarias que constituyen violaciones al derecho internacional de los Derechos Humanos y del Derecho Internacional Humanitario, lo que implica que, en materia de fallos sancionatorios se trata de la misma situación que había sido prevista por la Corte Constitucional, mas no respecto de autos de archivo. 
naturaleza punitiva. $2^{\text {a }}$ ) Debe existir una relación de identidad de: sujeto, hecho y bien jurídicos.

Debido a la excepcional eficacia del principio, por significar la inaplicación de una norma sancionadora o del doble procedimiento, se hace imprescindible la concurrencia de todos y cada uno los requisitos.

\subsection{Naturaleza punitiva de la actividad de la administración}

La aplicación del principio de non bis in idem presupone la concurrencia de dos o más actuaciones punitivas efectivas diferentes, conducentes a la imposición de una sanción. Pudiendo revestir estas últimas diversas modalidades tales como: multa, decomiso, destrucción de la cosa, inhabilitación (C-028/2006), cierre de establecimientos, entre otras. Por lo tanto, no opera cuando alguna de las consecuencias no tienen la consideración de sanción administrativa. Es el caso de: medidas restitutorias de la legalidad, la responsabilidad civil, las medidas provisionales, la confesión presunta, la acción de repetición, la privación de beneficios, los intereses moratorios, la constitución de garantías, o la responsabilidad fiscal, entre otras ${ }^{27}$.

En el caso de las medidas restitutorias de la legalidad conculcada, que impone la eliminación de los actos jurídicos contrarios al ordenamiento, como medida básica y fundamental del restablecimiento del propio orden jurídico. Es evidente que la eliminación del acto, o de la apariencia de acto, puede producir efectos desfavorables, pero no por ello su eliminación puede considerarse como una sanción ${ }^{28}$. En efecto, en esta medida no prevalece una finalidad de represión y de prevención, propia de la actividad sancionadora, sino que consiste únicamente en el restablecimiento del orden jurídico ${ }^{29}$.

Otro es el supuesto de la responsabilidad civil que tiene por finalidad el resarcimiento de los daños y perjuicios ${ }^{30}$ ocasionados por la conducta u omisión típica. Respecto a la concurrencia de estas instituciones se pronuncia Betancor Rodríguez, "un mismo hecho puede ser merecedor de una sanción administrativa y desencadenar la responsabilidad civil por los daños producidos, pero se trata de la coincidencia de dos instituciones jurídicas sobre un mismo hecho y las consecuencias jurídicas que llevan aparejadas sirven a fines distintos: en el primer caso, la finalidad represiva, mientras que en el segundo es reparadora"131.

\footnotetext{
27 El tema en el artículo Ramírez Torrado (2013), pp. 1-29.

${ }^{28}$ Corte Constitucional de Colombia, sentencia al respecto: C-391/2002.

29 Bermejo Vera (2001), p. 81 y Lozano Cutanda (1990).

30 Corte Constitucional de Colombia, sentencia al respecto: C-194/2005.

31 Betancor Rodríguez (2001), p. 1249.
} 
De otra parte, también se encuentran las medidas provisionales, es decir aquellos instrumentos que tienen como finalidad que no se continúen afectando o colocando en peligro los intereses de la Administración. Esta situación ha sido analizada entre otras ocasiones ${ }^{32}$, afirmando que tales medidas no quiebran el postulado, en tanto concurren con las sanciones, en la medida en que no ostentan una naturaleza punitiva, "ni comportan un juicio sobre la conducta de las personas a las que se les aplica, sino que corresponden simplemente a la constatación de hechos objetivos, que pueden llegar a afectar el buen funcionamiento de las instituciones". Muestras de esta situación sucede cuando la normativa contempla la suspensión para aquellas personas que han cometido conductas calificadas como gravísimas, y son suspendidas de sus actividades en tanto se adelanta el procedimiento administrativo sancionador ${ }^{33}$.

Por otro lado, la confesión ficta o presunta no se constituye en una sanción, porque aquélla se refiere a un "juicio lógico que efectúa el juez a partir de unas conductas omisivas del sujeto procesal, que le sirven de base para deducir otro, juicio, que por lo demás, puede ser controvertido o desvirtuado por la parte que se perjudica con la presunción"134.

Otro es el caso de la acción de repetición, propia del derecho administrativo, pues lo que se busca es la reparación de un daño ocasionado por el administrado y que la administración ha debido reparar y no la expresión del poder sancionador de la Administración ${ }^{35}$.

La desvinculación de una persona que se encuentra en carrera administrativa es otra de las medidas que tienen consecuencias gravosas para los administrados que no tienen un contenido sancionador. La carrera administrativa es una forma de vincularse con la administración que tiene por objetivo seleccionar a las mejores personas para el servicio del Estado y una vez vinculadas se les debe evaluar y controlar su desempeño. Evento en el cual el servidor público que no satisfaga las exigencias establecidas por la ley para laborar con el Estado, se podrá separar de su cargo, sin que con ello se esté manifestando el poder punitivo del Estado, porque lo que se busca es mejorar la calidad y la eficacia del servicio ${ }^{36}$.

Asimismo, la responsabilidad derivada de los procesos fiscales puede concurrir perfectamente con las sanciones administrativas, dada su naturaleza

${ }^{32}$ Corte Constitucional de Colombia, sentencia al respecto: C-1002/2005.

33 Corte Constitucional de Colombia, sentencia al respecto: C-406/1995.

${ }^{34}$ Corte Constitucional de Colombia, sentencia al respecto: C-622/1998.

35 Corte Constitucional de Colombia, sentencia al respecto: C-233/2002.

${ }^{36}$ Corte Constitucional de Colombia, sentencia al respecto: C-088/2002. 
resarcitoria ${ }^{37}$. Entonces, a un funcionario se le podrá imponer una multa producto de un proceso fiscal y simultáneamente una multa resultado de un proceso disciplinario ${ }^{38}$; ya que, a pesar de su igual denominación, estas últimas son resultado del incumplimiento de los deberes inherentes del servidor público, mientras que las primeras son derivadas del ejercicio de la vigilancia fiscal ${ }^{39}$.

Por último, se encuentra la figura de la privación de beneficios para los administrados. Así, con la entrega de beneficios se otorgan ventajas a aquellas personas que colaboran o tiene un comportamiento menos trasgresor con el ordenamiento frente a otras que se niegan a colaborar o infringen frecuentemente la legislación. Ejemplo de ello es lo que ocurre en el evento en que no se entrega permisos carcelarios a aquellas personas que hayan sido sancionadas disciplinariamente dentro de un penal ${ }^{40}$.

\subsection{La identidad de la actividad como presupuesto de la aplicación del principio}

La segunda de las condiciones, para que opere la prohibición bis in idem, consiste en la necesidad de identidad, tanto en el plano subjetivo, objetivo y de bien jurídico.

\subsubsection{Identidad subjetiva}

La aplicación del principio de non bis in idem exige que el poder sancionador sea ejercido en sede de una misma persona. A simple vista, la verificación de este elemento no presenta mayores inconvenientes, pues únicamente demanda que el sujeto pasivo sobre el que haya recaído o puede recaer una doble sanción o un segundo proceso sancionador sea la misma persona, con independencia del título de culpabilidad que resulte de la aplicación. Por consiguiente, basta con corroborar las características físicas e identidad del sujeto.

No obstante, esta simplicidad de los argumentos relacionados con la comprobación de la identidad subjetiva se quiebra en supuestos en los que una misma persona interviene en ejercicio de distintos títulos jurídicos. Entonces la identidad en comento no se circunscribirá a los rasgos que hacen a un individuo como único e irrepetible y que lo identifican y diferencian de otro, sino que la referida igualdad se podrá predicar, igualmente, en aquellos supuestos en que

37 Corte Constitucional de Colombia, sentencia al respecto: T-936/2005.

38 Corte Constitucional de Colombia, sentencia al respecto: C-189/1998; C-661/2000.

39 Corte Constitucional de Colombia, sentencia al respecto: T-525/1997.

40 Sentencia del Consejo de Estado, de 22 de noviembre de 2002, Consejero ponente: Gabriel Eduardo Mendoza Martelo, Número de radicación: 11001-03-24-000-2001-0029-01(6770), sección primera. 
dos o más sujetos se encuentren vinculados a través de determinada relación que obligue a la Administración a considerarlos como un solo sujeto. Con esto nos referimos a la identidad subjetiva desde un plano jurídico.

Son varias las hipótesis que se presentan respecto de la identidad subjetiva desde una óptica jurídica. Caso de la identidad entre los órganos de representación de las personas morales y la propia entidad, la identidad surgida por las obligaciones solidarias, o el supuesto de las diversas calidades que puede tener un individuo ante la Administración ${ }^{41}$. Sin embargo, será esta última la que tiene relación directa con este trabajo.

De este modo, en el marco de cualquier tipo de actividad que se encuentre controlada por la Administración, una misma persona puede tener una relación pura y simple con esta, que se inserta en aquellas relaciones denominadas como de sujeción general; y a su vez podría estar vinculada con la Administración a través de una relación de sujeción especial ${ }^{42}$.

En esta hipótesis la cuestión a determinar es si se comprende que se reitera el poder sancionador de la Administración cuando se impone una sanción a la persona, en tanto administrado general, y otra en razón de su vinculación especial con la Administración, por un mismo hecho. Frente a este interrogante la solución de la Corte Constitucional es pacifica, ya que está plenamente aceptado por la doctrina constitucional que una persona que se encuentra encargada de la protección de ciertos bienes jurídicos, y asimismo deba cumplir con los mandatos generales como ciudadano común, puede ser sancionada doblemente consecuencia de un mismo hecho. Lo anterior, teniendo en cuenta que a pesar de tratarse de un mismo sujeto éste mantiene con la Administración una relación diversa a la que sostiene con aquella en tanto que ciudadano. Por tanto, no existe una identidad subjetiva jurídica en el caso en cuestión.

\subsubsection{Identidad del bien jurídico tutelado}

La identidad en el bien jurídico protegido en las infracciones administrativas es el segundo elemento necesario para que el principio non bis in idem opere. Queremos decir con ello, que para que una persona sea sancionada o se le siga un doble proceso, tanto la segunda sanción, como el segundo procedimiento deben responder a bienes jurídicos diversos.

Este elemento lejos de presentar una claridad deseada se muestra un tanto oscuro en algunos aspectos como son: su denominación y objeto de aplicación. La falta de una claridad deseada se evidencia de igual modo en la legislación sectorial que no se ocupa de la cuestión.

41 LeÓN Villalba (1998), p. 482.

42 Sánchez Herrera (2005), p. 17; Gómez Pavajeau y Molano lópez (2007). 
Frente al interrogante: ¿Qué bien jurídico conforma el segundo requisito del non bis in idem?, respondemos que no hay una respuesta contundente, en la medida en que la doctrina constitucional ha limitado exclusivamente sus esfuerzos a precisar los alcances de este requisito, en el caso de los efectos del non bis in idem inter especie. Sin embargo, no se ha adentrado en la extensión del requisito al interior del sector netamente administrativo.

Entonces, en el caso del bien jurídico inter especie, este asunto ha sido tratado de forma pacífica por la doctrina constitucional ${ }^{43}$ en la medida que ha identificado como bienes jurídicos diversos los protegidos por las distintas jurisdicciones ${ }^{44}$. Nos referimos con estas últimas a: la penal, administrativa: correctiva o disciplinaria, que salvaguardan intereses diversos, ya que confrontan "normas de categoría, contenido y alcance distinto"45.

Esta cuestión se ha justificado; ya que de sancionar una sola vez al administrado que lesiona con su actuación diversos sectores del ordenamiento se dejarían impunes las agresiones de los bienes jurídicos, protegidos por los distintos sectores, con la inevitable consecuencia de generar una alarma social sobre "las políticas y acciones de la justicia administrativa y judicial"46.

De otra parte, en lo que corresponde con el bien jurídico intra especie, al no existir una respuesta por parte del legislador, como tampoco de la doctrina constitucional sobre el alcance del bien jurídico al interior del derecho administrativo, se suscita la cuestión de determinar cuál es el bien jurídico relevante como elemento integrante del principio en cuestión: ¿Será acaso el que protege las infracciones independientemente consideradas o, por el contrario, será aquel que se encuentra comprendido en una norma en su conjunto?

La primera opción está orientada a analizar cada uno de los elementos normativos que constituyen la infracción, pues en la medida que dichos elementos queden definidos claramente en la descripción típica, el legislador asegurará la protección del bien jurídico. En este sentido, se puede recurrir a la afirmación planteada por Jescheck: "el bien jurídico es el concepto central del tipo, en torno al que giran todos los elementos objetivos y subjetivos y, un importante instrumento de la interpretación"47.

Podríamos enfrentarnos a dos o más infracciones que si bien a simple vista parecieran iguales contienen elementos normativos que las diferencian y hacen

${ }^{43}$ Corte Constitucional de Colombia, sentencias al respecto: C-319/1994; C-259/1995; C-870/2002; C-393/2006; T-161/2009.

${ }^{44}$ Corte Constitucional de Colombia, sentencia al respecto: C-181/2002.

45 Corte Constitucional de Colombia, sentencia al respecto: T-413/1992.

46 Corte Constitucional de Colombia, sentencia al respecto: C-620/2001.

47 JESCHECK (1981), p. 352. 
posible la reiteración punitiva o la dualidad de procedimientos. En este caso vale la pena traer a colación el ejemplo previsto por Nieto García ${ }^{48}$, el autor sostiene que las comunidades autónomas españolas, conscientes de la importancia de la protección del medio ambiente y de la repercusión que pueden traer los vertidos al mar en la pureza del agua, han dictado normas que sancionan conductas muy parecidas a las previstas en normativas ambientales, pero cuidándose de incluir elementos que las diferencien.

Resultado de la aplicación de este camino, el trabajo del operador jurídico será el de analizar detalladamente los ingredientes normativos que el legislador haya incluido en cada una de las infracciones para determinar si estamos ante una conducta que lesiona un mismo bien jurídico o, por el contrario, se trata de dos bienes jurídicos diversos. Pues en la medida que estos rasgos hayan sido previstos en el mismo tipo podremos establecer si nos enfrentamos al mismo bien o si, por el contrario, hacemos frente a dos bienes que aunque muy cercanos buscan salvaguardar intereses diversos para la comunidad. Esta parece ser la postura de la Corte Constitucional que ha exigido la identidad de los fundamentos normativos como requisito indispensable del non bis in idem ${ }^{49}$.

De otra parte, en el segundo caso, cuando el camino escogido es el de interpretar el contenido del concepto de bien jurídico desde el conjunto de la norma y no desde los elementos normativos que integran la infracción se nos impone una lectura diversa. En este caso, de lo que se trata es de dos normas que contienen una descripción típica muy semejante y que a primera vista pareciera proteger el mismo bien jurídico. En este sentido, se optaría por la lectura del texto normativo en su conjunto para a partir de ahí desentrañar la verdadera intención del legislador y con ello precisar el bien jurídico que se buscaba proteger. Para lograr este objetivo, nos debemos remitir a los antecedentes que motivaron la norma o los debates legislativos que se dieron durante su proceso de elaboración o a su exposición de motivos, con el fin de indagar por el bien jurídico que el legislador intentó preservar en la ley.

Sin embargo, somos de la opinión que esta solución es solo posible para los casos en que la descripción del tipo legal no solucione la cuestión. Pues estamos convencidos que lo realmente importante es que el bien jurídico se haya plasmado en el tipo en concreto; y solo en la medida que éste se encuentre comprendido en la respectiva infracción, podrá ser protegido. No obstante, somos conscientes que si las infracciones aludidas no entregan una solución a la cuestión no nos serviría de nada acudir simplemente a lo consagrado en la infracción, pues al ser exactamente iguales nuestra duda no sería aclarada. Por lo

48 Nieto García (2005), p. 390.

${ }^{49}$ Corte Constitucional de Colombia, sentencia al respecto: C-471/2006. 
anterior, nos vemos obligados a recurrir al cuerpo de la norma o igualmente a la exposición de motivos del texto legal para desentrañar el espíritu del legislador.

\subsubsection{Identidad objetiva o fáctica}

Esta condición se erige como el tercer requisito del principio y significa que un hecho no puede ser sancionado o procesado en dos ocasiones. Es en el elemento objetivo o fáctico donde se observa con mayor nitidez el origen procesal del principio, porque esta faceta ha marcado profundamente el significado del requisito en el ámbito material, hasta el punto de confundirlo en ocasiones.

En lo que respecta a la faceta material del principio $^{50}$, se da en el evento en que al administrado, no se le hayan abierto ningún proceso administrativo, pero que con su actuación se le pueden abrir dos o incluso más expedientes por autoridades administrativas diversas. Es esta oportunidad, aun cuando no existe una quiebra del principio, ya que no se ha impuesto una sanción o se ha abierto un proceso, el administrado se podría encontrar, ad portas, de que ello ocurriese.

La identidad fáctica como requisito del principio non bis in idem puede tener dos lecturas. La primera de ellas se refiere a la normativa, y la segunda a la histórica de los hechos. Sin embargo, la interpretación que se ha impuesto ha sido la normativa, en la que interesan los hechos con relevancia normativa, es decir, aquellas situaciones que tengan determinadas características que se ajustan al bien jurídico protegido en la infracción ${ }^{51}$, y no los hechos desde una perspectiva espacio-temporal o histórica (León Villalba: 1998).

Y la perspectiva procesal del principio que corresponde a la prohibición que una persona soporte juicios sucesivos o simultáneos por el mismo hecho. En la T-162/ 1998 se estableció: "esas particularidades fueron señaladas como la identidad de: i) motivos; ii) juicios; iii) hechos, iv) asunto v) objeto y vi) causa".

\section{El Derecho disciplinario del abogado ${ }^{52}$}

La doctrina manifiesta que en la alta antigüedad no existía una profesión equivalente a la abogacía, sino que la defensa de las personas estaba encomendada a los sabios, quienes se caracterizaban por su elocuencia. Así, Monroy $\mathrm{Cabra}^{53}$ relata que en Atenas las funciones de los abogados las desempeñaban los amigos con aptitudes para la oratoria. Era la fuerza persuasiva de la elo-

50 Corte Constitucional de Colombia, sentencia al respecto: C-526/2003.

51 Cano Campos (2001), pp. 191-249.

52 Al respecto: Restrepo Méndez (2008); Reyes Cuartas (2003).

53 Monroy Cabra (2002), p. 23. 
cuencia la que garantizaba el éxito incluso contra la verdad. A estas personas se les denominó logógrafos. Posteriormente Solón reglamentó la abogacía y le dio el carácter de función pública con prestigio religioso.

Fue en Roma donde se acuñó el término Abogado, proveniente de la voz latina "ad vocatus" (Advocare: Convocar), que significa Ilamado a, o llamado para, para representar a las personas versadas en leyes que ejercían la defensa jurídica. Abogado es "perito en derecho que se dedica a defender en juicio los derechos de los litigantes y a dictaminar sobre las cuestiones judiciales que se le consultan"154.

En Colombia es abogado aquel que obtiene el correspondiente título universitario de conformidad con las exigencias académicas y legales (artículo $3^{\circ}$ del Decreto 196 de 1971), aun cuando se disciplina como tales sólo a quienes "en ejercicio de su profesión cumplan con la misión de asesorar, patrocinar y asistir a las personas naturales o jurídicas, tanto de derecho privado como de derecho público, en la ordenación y desenvolvimiento de sus relaciones jurídicas así se encuentren excluidos o suspendidos del ejercicio de la profesión y quienes actúen con licencia provisional. Se entienden cobijados bajo este régimen los abogados que desempeñen funciones públicas relacionadas con dicho ejercicio, así como los curadores ad litem. Igualmente, lo serán los abogados que en representación de una firma o asociación de abogados suscriban contratos de prestación de servicios profesionales a cualquier título" (artículo 19 ley $\mathrm{N}^{\circ} 1123$ de 2007), lo que se compadece con las principales misiones de dichos profesionales, cuales son defender en justicia los derechos de la sociedad y de los particulares y asesorar, patrocinar y asistir a las personas en la ordenación y desenvolvimiento de sus relaciones jurídicas (artículo $2^{\circ}$ decreto 196 de 1971).

Los abogados son considerados coadyuvadores de la función pública del Estado, lo que hace comprensible que se exija de ellos un nítido ejercicio profesional. De hecho, la abogacía tiene como función social la de colaborar con las autoridades en la conservación y perfeccionamiento del orden jurídico del país, y en la realización de una recta y cumplida administración de justicia (artículo $1^{\circ}$ Decreto 196 de 1971).

Respecto de los abogados existe una potestad disciplinaria profesional que en Colombia está asignada por mandato constitucional al Consejo Superior de la Judicatura y a sus seccionales.

Según señaló la Corte Constitucional "los profesionales del derecho deben dar ejemplo de idoneidad, eficiencia y moralidad en el desempeño de sus actividades y estar comprometidos en los ideales y el valor de la justicia, los cuales constituyen la esencia y el fundamento para la vigencia del orden polí-

${ }^{54}$ Delgado (1997), p. 2. 
tico, económico y social justo que preconiza la actual Constitución Política"155, por tanto, si bien se les protege el derecho al trabajo, no por ello deben estar despojados de deberes y obligaciones ${ }^{56}$, máxime cuando el artículo 26 constitucional establece la obligación de las autoridades de inspeccionar y vigilar el ejercicio de las profesiones.

Es de destacar que la Constitución de 1886 establecía en su artículo 44 que "(...) las autoridades inspeccionaran las industrias y las profesiones en lo relativo a la moralidad, la seguridad y la salubridad públicas (...)" y que mediante acto legislativo número 1 de 1918, esta norma fue sustituida (o mejor, complementada), en el sentido de exigir títulos de idoneidad para el ejercicio de la abogacía, lo que se desarrolló mediante las leyes $\mathrm{N}^{\circ}$ s. 62 de 1928 y 21 de 1931, complementadas por la ley № 69 de 1945. Las leyes comentadas no eran propiamente estatutos deontológicos de manera tal que el régimen disciplinario era incompleto e impreciso ${ }^{57}$, hasta que se expidió el Decreto 196 de 1971, el cual se aplicó en materia disciplinaria abogadil hasta el mes de mayo del año $2007^{58}$ cuando entró a regir la ley $N^{\circ} 1123$ del mismo año, que se encuentra vigente, y constituye el Código Disciplinario del Abogado, cuyo primer título, se ocupa de los principios rectores del derecho disciplinario, entre ellos el non bis in idem, (art. $\left.9^{\circ}\right)$.

\section{El derecho a no ser sancionado dos veces en el derecho disciplinario del abogado}

A continuación se expone una serie de hipótesis frente a las cuales se ha planteado la posibilidad de quiebra del principio de non bis in idem en el campo disciplinario abogadil.

\subsection{Abogados que desempeñan funciones públicas}

En torno a este aspecto, se ha presentado quizá el punto más álgido de conflicto frente a la posibilidad de doble procesamiento por unos mismos hechos a que pueden verse expuestos los abogados, toda vez que el artículo 19 de la ley $\mathrm{N}^{\mathrm{o}} 1123$ de 2007, faculta a la jurisdicción disciplinaria en cabeza del Consejo Superior de la Judicatura para disciplinar a los abogados que desempeñen

\footnotetext{
${ }^{55}$ Corte Constitucional de Colombia, sentencia al respecto: C-540/1993.

${ }^{56}$ Corte Constitucional de Colombia, sentencia al respecto: T-408 de 2002.

${ }^{57}$ Monror (2002), p. 31.

${ }^{58}$ Se destaca que por respeto al principio de legalidad el Decreto 194 de 1971 continúa regulando lo concerniente a las conductas cometidas antes de la entrada en vigencia la ley $N^{\circ} 1123$ de 2007, aun cuando los aspectos procesales se rijan por esta última, excepto para los procesos al cinco (5) de mayo del año en comento tuvieran auto de cargos.
} 
funciones públicas cuando estas estén relacionadas con el ejercicio abogadil. Así mismo, al ostentar dichos profesionales también la calidad de servidores públicos, pueden ser disciplinables, además, por la Procuraduría General de la Nación o por las Oficinas de Control Interno Disciplinario, según el caso.

Si bien inicialmente se planteó que la norma en comento constituía una extralimitación del legislativo atribuyendo al Consejo Superior de la Judicatura una función que debe entenderse conferida a la Procuraduría General de la Nación, por el vínculo de sujeción especial que existe entre los servidores y el Estado, lo cierto es que esta norma lo que hizo fue establecer dos regímenes disciplinarios para quienes ostentaran la doble condición de abogados y servidores públicos, generalizando lo que ya para el caso de los defensores públicos había establecido el artículo $8^{\circ}$ de la ley No 941 de 2005, el cual consagra que: "los abogados que presten el servicio de asistencia y representación judicial en el Sistema Nacional de Defensoría Pública estarán sujetos, según el caso, para el ejercicio de sus derechos y cumplimiento de sus obligaciones, a las responsabilidades y sanciones que les impone su condición de servidores públicos o de particulares que cumplen funciones públicas y de sus faltas en el ejercicio de la profesión de abogado conocerán las Salas Jurisdiccionales Disciplinarias de los Consejos Seccionales y Superior de la Judicatura en sus respectivas instancias (...)".

Y es que el abogado -servidor público- que desempeña funciones públicas relacionadas con el ejercicio de su profesión, se encuentra sometido conforme a la norma en comento a los regímenes funcionarial y el abogadil, luego se hace necesario determinar si entre estos existe "identidad de fundamento" o por el contrario se trata de modalidades diversas del ius puniendi, encontrando que frente a tal interrogante se han expuesto diversas posiciones que defienden alguna de las dos posturas.

Así, Barrera Núñez ${ }^{59}$ parece inclinarse por la primera cuando asegura que no existe la posibilidad de que dos autoridades distintas posean potestad disciplinaria respecto de un mismo funcionario lo que, en su sentir sí constituiría desconocimiento del non bis in idem. Para dicho autor, si bien la norma cuestionada permite hablar de la existencia de dos autoridades con potestad disciplinaria respecto de un mismo sujeto, la intención del legislador fue vincular como disciplinables sólo a los servidores públicos que actúan en ejercicio de un poder especial que limita sus facultades y, exclusivamente con relación al ejercicio del derecho de postulación.

En similar sentido, Sánchez Herrera sostiene que la posibilidad de dos juicios atenta contra el principio de non bis in idem y por tanto habría que determinar

59 Barrera NúNẽez (2008), p. 80. 
si el comportamiento reprochable se encuentra esencialmente vinculado con la función pública o con la ética profesional, para de esa forma establecer quién es la autoridad competente para realizar el disciplinamiento ${ }^{60}$.

En contraposición, Díaz Brieva no encuentra inconveniente en que un servidor público abogado pueda ser doblemente disciplinado por autoridades distintas ${ }^{61}$. Igualmente, Roa Salguero sostuvo que el derecho disciplinario que se aplica a los abogados es distinto al que se aplica a los funcionarios no sólo porque aquel es jurisdiccional y este administrativo, sino porque además tienen una finalidad diversa. Así, según afirmó el autor en comento, "en tanto la acción disciplinaria que debate la responsabilidad del abogado en ejercicio de su profesión pretende garantizar la efectividad y buen ejercicio de la misma (...), la acción disciplinaria administrativa propende a la buena marcha e imagen de la administración pública"'62.

La posibilidad de acumular dos sanciones disciplinarias por un mismo hecho es la adoptada por la Corte Constitucional en sentencia C-899/2011, en la que aseguró que "las sanciones que están llamados a imponer los consejos seccionales y superior de la Judicatura difieren en su naturaleza y objeto de las que debe imponer el Procurador General de la Nación, razón por la que una misma conducta puede dar origen a que se active la competencia de esos dos entes, sin que se desconozca la prohibición de doble juzgamiento que establece el artículo 29 Constitucional".

De este modo, el bien jurídico tutelado por el derecho disciplinario funcionarial está integrado por los distintos principios que rigen la función pública, mientras que en el derecho disciplinario abogadil se habla de la dignidad de la profesión (art. 30); el decoro profesional (art. 31); el respeto debido a la administración de justicia y a las autoridades administrativas (art. 32); la recta y leal realización de la justicia y los fines del Estado (art. 33); la lealtad con el cliente (art. 34); la honradez que debe observar el abogado (art. 35); la lealtad y honradez debida a los colegas (art. 36); la debida diligencia profesional (art. 37); el deber de prevenir litigios y facilitar los mecanismos de solución alternativa de conflictos (artículo 38), los cuales se corresponden con los deberes que tiene el profesional del derecho.

Siendo así, es aceptado que se establezca una dualidad de sanciones y procesos, sin que con ello se vulnere el principio de non bis in idem, aun cuando indudablemente para quienes poseen la doble condición de abogados

\footnotetext{
60 Sánchez Herrera (2005), p. 71.

${ }^{61}$ Díaz Brieva (2007), p. 193.

62 Roa Salguero (2009), p. 5.
} 
y servidores públicos resulta más onerosa y confusa la defensa disciplinaria ${ }^{63}$, máxime cuando en uno de los casos la sanción puede ser controvertida judicialmente mientras que en el otro no. Igualmente, es posible que las decisiones adoptadas desde perspectivas disciplinarias distintas resulte ser asimétrica, de manera tal que mientras para un régimen se imponga sanción para el otro resulte la absolución ${ }^{64}$.

Si bien este es el panorama reinante en la doctrina científica y constitucional, este escenario nos genera varios interrogantes, derivados de los propios argumentos de la Corte, y ellos se tratan de: ¿no es acaso el ius puniendi del Estado uno solo?, sin olvidar que este se encuentra integrado por varias subespecies, entre las cuales, claro está, se encuentra la disciplinaria. Situación que nos plantea otra inquietud: la reiteración del poder derivado de cada una de las subespecies, que lo conforma, ¿implicaría la violación al principio en cuestión?

Otra cuestión que nos inquieta es ¿en qué consiste la real diferencia entre los dos ordenamientos jurídicos disciplinarios (el que protege la Procuraduría y el que asimismo salvaguarda el Consejo Superior de la Judicatura)?, pues ambos tienen como común denominador las relaciones de sujeción especial que permiten la aplicación del derecho disciplinario; o quizás esta interpretación, de que se trata de bienes jurídico diversos (que protegen sendos órganos) obedezca más bien a la necesidad de "respetar" la autonomía de cada uno de estos órganos (al ser órganos independientes dentro de la infraestructura del estado) que al deber de proteger el derecho del administrado a no ser sancionado dos veces ${ }^{65}$.

\subsection{Tipos disciplinarios en blanco y similitud de descripciones típicas}

Si bien el principio de legalidad establece que la acción u omisión ${ }^{66}$ realizada por el sujeto activo de la infracción debe estar expresamente proscrita por la 1 ley ${ }^{67}$, dada la naturaleza misma del derecho disciplinario y la imposibilidad del legislador de conocer o enunciar expresamente todos los casos posiblemente

\footnotetext{
${ }^{63}$ La aclaración anterior, por cuanto si bien la Sala Disciplinaria del Consejo Superior de la Judicatura, con ponencia de la doctora María Mercedes López Mora, en providencia del 31 de marzo de dos mil ocho (2008) proferida dentro del radicado 110011102000200800254 01, planteó la necesidad de que las decisiones fueran congruentes en los distintos regímenes, la Corte Constitucional, en sentencia T-161 de 2009, precisó que no puede perderse de vista que cada procedimiento tiene finalidades distintas.

64 Gómez Pavajeau (2009), p. 251.

${ }_{65}$ Al respecto la C-899/2011: “de aceptarse que un mismo hecho no puede dar origen a actuaciones o procesos diversos frente a un mismo individuo, podría generar consecuencias tales como que una vez una autoridad determinada inicie o profiera un resultado concreto frente a un individuo, otras pierdan su competencia para cumplir la función que les corresponde".

${ }^{66}$ LÓPEz Nieto (2002), p. 64.

67 BarRera NúÑ̃ez (2008), p. 13.
} 
constitutivos de faltas, se ha dicho que el principio nullum crimen sine lege goza aquí de gran flexibilidad ${ }^{68}$, o, en términos de la Corte Constitucional, menor precisión que en las normas penales.

Lo manifestado implica que se aceptan tipos abiertos o conceptos jurídicos indeterminados, pero que sean determinables por el operador jurídico en aplicación de parámetros de valor o experiencia incorporados al ordenamiento jurídico.

Así, aunque el principio de legalidad fue instituido como freno a la arbitrariedad y abusos de poder por parte del Estado (lo que incluye como exigencia el principio de lex certa o determinación, en virtud del cual el legislador debe definir de forma clara y comprensible los tipos sancionables) ${ }^{69}$, el transcurrir del tiempo y la evolución de las distintas doctrinas que lo justifican, han permitido en él varias transformaciones, siendo oportuno destacar que incluso en materia penal se ha desarrollado la existencia de normas que no describen exhaustivamente la conducta, sino que exigen un complemento que se da para cada caso concreto ${ }^{70}$.

Esas normas son justamente lo que se conoce como tipos abiertos, los cuales tienen una función de advertencia, pues le indican al ciudadano el límite entre lo prohibido y lo permitido y, en consecuencia, se ha dicho que no constituyen un desconocimiento del principio de legalidad ${ }^{71}$, sino una morigeración de éste ${ }^{72}$.

En el derecho disciplinario abogadil colombiano se combina la utilización de tipos disciplinarios abiertos y cerrados. Así mismo, es usual que se presente mucha similitud entre diferentes descripciones típicas, de manera tal que la diferencia entre una falta y otra puede ser incluso imperceptible.

Frente a tal situación, surge preguntarse si la misma permite el quebrantamiento del derecho a no ser sancionado dos veces por lo mismo. Lo anterior, por cuanto, al corresponder al operador disciplinario complementar y definir la conducta prohibida, ¿es posible que éste en un momento determinado encuentre que encuadra en una falta $X$ y después, ante un nuevo proceso, la adecue en una falta $Y$ ?

Al respecto, se hace oportuno recordar que, conforme lo sostuvo la Corte Constitucional en la sentencia T-145 de 1993, con el principio del non bis in idem se pretende: "evitar que las personas sean sometidas por el Estado a permanentes y sucesivas investigaciones y sanciones a partir de un mismo

\footnotetext{
68 ISAZA (2009), p. 98.

69 Fernández Cruz (1998), pp. 145-152.

${ }^{70}$ Corte Constitucional de Colombia, sentencia al respecto: C-393 de 2006.

71 Corte Constitucional de Colombia, sentencia al respecto: C-333 de 2001.

72 Corte Constitucional de Colombia, sentencia al respecto: C-762 de 2009.
} 
comportamiento, colocándolas en estado de absoluta indefensión y de continua ansiedad e inseguridad". Siendo así, la prohibición de doble juzgamiento excluye la posibilidad de dar a los hechos una denominación jurídica distinta en un nuevo proceso.

\subsection{Concurso de faltas}

Se dice que hay concurso de faltas cuando con una o varias acciones u omisiones se infringen varias disposiciones de la ley disciplinaria. Un ejemplo típico de concurso de faltas se da frente al abogado que, a pesar de encontrarse suspendido o excluido de la profesión, incurre en ejercicio ilegal de la abogacía, y al mismo tiempo encuadra su conducta en otro de los comportamientos descritos como falta.

Este individuo, con un mismo actuar quebranta doblemente el estatuto ético abogadil, lo que lo llevaría a responder no sólo por la incompatibilidad prevista en el numeral 4 del artículo 29 de la ley № 1123 de 2007, sino también por cualquier otra falta en la que con su actuar incurra ${ }^{73}$, sin que por ello sea posible hablar de desconocimiento del principio del non bis in idem, pues, como se dijo, lo que se presenta es un concurso real de faltas disciplinarias, en el que de hecho se lesionan diversos bienes jurídicos.

Ahora bien, cosa distinta es que el concurso no sea real, sino aparente, esto es, que "una misma situación de hecho desplegada por el autor pareciera adecuarse a las previsiones de varios tipos penales, cuando en verdad una sola de estas normas es aplicable al caso en concreto" (Corte Suprema de Justicia. Sala de Casación Penal. Proceso No 27383. Providencia del veinticinco de julio de dos mil siete).

En tal evento, si se disciplina a un sujeto determinado o se le impone sanción por varias faltas que se encuentran subsumidas en otras, se ha establecido que se incurre en vulneración del principio del non bis in ídem. Así, mírese que frente a las faltas descritas en los numerales 1 y 2 del artículo $55^{74}$ del Decreto 196 de $1971^{75}$, aplicable aún para las conductas acaecidas durante su

\footnotetext{
73 Barrera NúÑez (2008), p. 79.

${ }^{74}$ ARTíCULO 55. "Incurre en falta a la debida diligencia profesional: 1o. El abogado que injustificadamente demore la iniciación o prosecución de las gestiones que le han sido encomendadas o deje de hacer oportunamente las diligencias propias de la actuación profesional, y 2o. El abogado que sin justa causa descuido o abandone el asunto de que se haya encargado".

${ }^{75}$ Las faltas contra la debida diligencia profesional aparecen consagradas en el artículo 37 de la ley $N^{\circ} 1123$ de 2007, que a la letra dice "ARTíCULO 37. Constituyen faltas a la debida diligencia profesional: 1. Demorar la iniciación o prosecución de las gestiones encomendadas o dejar de hacer oportunamente las diligencias propias de la actuación profesional, descuidarlas o abandonarlas. 2. Omitir o retardar la rendición escrita de informes de la gestión en los términos pactados en el mandato
} 
vigencia, el Consejo Superior de la Judicatura, en providencia del Cuatro (4) de junio de dos mil nueve (2009), proferida con ponencia de MARÍA MERCEDES LÓPEZ MORA, dentro del radicado № 4400110200020060087501, la Sala Jurisdiccional Disciplinaria del Consejo Superior de la Judicatura manifestó que "(...) no puede atribuírsele responsabilidad alguna a la togada investigada por una falta que está subsumida en otra, pues de ser así, estaríamos en presencia de una doble imputación disciplinaria por los mismos hechos y por ende una violación al principio del NON BIS IN IDEM".

También en torno a las conductas descritas en los numerales 3 y 4 del Decreto 196 de 1971, se ha presentado la problemática expuesta. Así, en providencia del once (11) de mayo de dos mil once (2011), proferida con ponencia de PEDRO ALONSO SANABRIA BUITRAGO dentro del radicado 1700111020002010 0029701 la Sala Disciplinaria del Consejo Superior de la Judicatura aseguró que "disiente (...) de las apreciaciones hechas por la Seccional de instancia en lo que tiene que ver con la falta contenida en el artículo 54.4 del Decreto 196 de 1971, pues el sustento fáctico de tal acusación es haber utilizado en provecho propio tales dineros, conducta que hace parte del retención de los mismos, la cual igualmente sufrió el quejoso, luego mal podría censurarse dos veces una misma situación fáctica".

En los casos planteados se observa que el desconocimiento del principio del non bis in idem guarda relación con una mala práctica consistente en hacer adecuaciones múltiples sin verificar si efectivamente hay un concurso de faltas y finalmente a imponer sanciones por todas las faltas imputadas.

\section{Casos de conexidad}

La conexidad ha sido entendida como: la "garantía de que bajo ciertas y determinadas circunstancias se preserve la unidad procesal, se garantice el adelantamiento de un único proceso, respetando los principios de unidad procesal, concentración probatoria, eficacia del procedimiento, eficacia de la justicia y celeridad"76. Entonces, cuando se habla de conexidad no se hace referencia a un mismo hecho, de manera tal que hay ausencia de identidad fáctica y por tanto, a simple vista no sería posible plantear un quebrantamiento del principio del non bis in idem.

o cuando le sean solicitados por el cliente, y en todo caso al concluir la gestión profesional. 3. Obrar con negligencia en la administración de los recursos aportados por el cliente para cubrir los gastos del asunto encomendado. 4. Omitir o retardar el reporte a los Juzgados de los abonos a las obligaciones que se están cobrando judicialmente".

76 Sentencia proferida el once (11) de febrero de dos mil once (2011), por la Sala de Casación Penal de la Corte Suprema de Justicia, con ponencia de Augusto J. Ibáñez Guzmán. Proceso 31228. 
De hecho, así lo sostuvo la Corte Constitucional en sentencia C-357/1999, en la que manifestó que cuando se investigaban hechos conexos por separado no se desconoce el principio del non bis in idem, pues "si las conductas imputadas no son las mismas, la investigación y el juzgamiento de una de ellas no inhibe al Estado para asumir el conocimiento de otra u otras diferentes, atribuidas a la misma persona, pues ésta debe responder por todas, sin que la actividad jurisdiccional pueda ser frustrada bajo el argumento de que se vulnera el principio non bis in idem, cuyo supuesto básico radica en que se trate de los mismos hechos".

No obstante lo manifestado, no deja de ser problemático que existiendo la posibilidad de recibir una sola sanción, eventualmente tengan que recibirse varias por no procurarse la unidad procesal, circunstancia que se hace más cuestionable si se está ante la reiteración de una misma conducta (mismo modus operandi).

Así, para ejemplificar el problema planteado, podría pensarse en un abogado que descubre que otro lo desplazó injustamente en varios procesos que le atendía a un mismo cliente. Si el abogado lesionado decide presentar una sola denuncia refiriéndose a todos los casos, el procesado recibirá una sola sanción obviamente impuesta en consideración a las circunstancias que determinaron el concurso de faltas, pero si aquel opta por presentar una queja por separado para cada situación fáctica, el denunciado recibirá tantas sanciones como denuncias se hubieren interpuesto.

Lo expresado implica que, a pesar de no existir discusión en cuanto a que los hechos conexos deben investigarse bajo la misma cuerda procesal, no existe en el derecho disciplinario abogadil una norma que establezca el procedimiento a seguir para que esto se materialice, generando si bien no un quebrantamiento del principio de non bis in idem por las razones ya expuestas, sí una pluralidad de sanciones, cuando bien pudo tratarse de una sola.

\section{Caso de las infracciones mediales}

La infracción medial es aquella que se comete por ser necesaria para la comisión de otra, caso en el cual se presenta un concurso aparente de tipos que se resuelve aplicando la sanción prevista para la sanción más grave. De este modo, las infracciones mediales no pueden ser sancionadas autónomamente, ya que de esta manera se produciría un quebrantamiento del principio del non bis in idem, no obstante, los operadores disciplinarios frecuentemente desconocen la regla correspondiente, lo que genera que en la práctica se vulnere el principio.

Para este caso, cítese a manera de ejemplo las conductas descritas en los numerales 4 y 5 del artículo 35 de la ley № 1123 de 2007, que tipifican como faltas a la honradez del abogado de un lado "No entregar a quien correspon- 
da y a la menor brevedad posible dineros, bienes o documentos recibidos en virtud de la gestión profesional, o demorar la comunicación de este recibo" y de otro "No rendir, a la menor brevedad posible, a quien corresponda, las cuentas o informes de la gestión o manejo de los bienes cuya guarda, disposición o administración le hayan sido confiados por virtud del mandato, o con ocasión del mismo" y que frecuentemente son imputadas partiendo de un mismo supuesto fáctico.

Frente a estas, la Sala Disciplinaria del Consejo Superior de la Judicatura, tuvo la oportunidad de pronunciarse en sentencia del 13 de enero de 2011, proferida con ponencia de JORGE ARMANDO OTÁLORA GÓMEZ, dentro del radicado No. 700011102000200700264 01, en la cual sostuvo que " en el sub examine no pueden cohabitar como faltas independientes las imputadas al inculpado y producto de las cuales se le derivó responsabilidad jurídica, pues si se atiende una teoría final de la acción, no se puede soportar la existencia autónoma de la falta de rendición de cuentas al cliente, por cuanto la retención de dineros termina subsumiéndola, pues si ontológicamente se le reprocha al inculpado el hecho de haber retenido los dineros recibidos por cuenta de su cliente, el hecho de no haber informado o rendido cuentas de su gestión, no puede tildarse una lesión independiente al referido bien jurídico, por cuanto dicha omisión debe ser mirada como el medio utilizado para ocultar la retención, es decir existe una relación de medio a fin y frente a tal postura de orden conceptual, no están dados los presupuestos para sostener una autonomía en la conducta imputada por la primera instancia".

\subsection{Decisión inhibitoria}

La decisión inhibitoria es aquella que elude definir la cuestión de fondo planteada y por tanto carece del efecto de cosa juzgada. Así mismo, la Corte Constitucional en sentencia C-247 de 1995 aseguró que: "es entendido que el carácter de la cosa juzgada solamente lo tienen las providencias que han entrado a definir el fondo de la cuestión planteada, razón por la cual no puede afirmarse que cuando (...) profiera decisión inhibitoria haya sido juzgado el caso (...) Precisamente, en tales casos nada se ha resuelto, de lo cual se desprende que es posible iniciar nueva actuación sin que se quebranten los principios de cosa juzgada y 'non bis in idem'".

En materia disciplinaria abogadil, es posible proferir decisión inhibitoria frente a las eventualidades consagradas en el artículo 69 de la ley $\mathrm{N}^{\circ} 1123$ de 2007, según el cual "Las informaciones y quejas falsas o temerarias, referidas a hechos disciplinariamente irrelevantes, de imposible ocurrencia o que sean presentados de manera absolutamente inconcreta o difusa, darán lugar a inhibirse de iniciar actuación". 
Lo dicho implica que en los eventos señalados en la norma en comento el funcionario del conocimiento adopta una decisión que no adquiere la fuerza vinculante exigida en el artículo $9^{\circ}$ de la ley $N^{\circ} 1123$ de 2007 para que se aplique el non bis in idem, lo que, según lo planteado por Santamaría Pastor ${ }^{77}$ puede ser el vehículo a través del cual se desconoce dicho principio.

Tal circunstancia no aparece justificada, pues, excepto el caso de la inconcreción que impide saber con certeza cuáles son los hechos investigados, no existe una razón válida para que en las otras eventualidades consagradas en la norma la decisión mediante la cual se resuelve de plano no ofrezca seguridad jurídica.

\section{Variación de cargos}

Dado que en materia disciplinaria abogadil rige el principio de la oralidad, al finalizar la primera audiencia el funcionario del conocimiento calificará la actuación ya sea con auto de archivo o de cargos, evento este último en el cual, con base en las probanzas recaudadas realizará la imputación fáctica y jurídica al procesado. Así, formular cargos implica hacer una valoración de la situación planteada, descartar la comisión de unas posibles faltas para presumir la incursión en otras, poniendo de esa forma fin a un estadio procesal para pasar al siguiente: el juzgamiento.

Ahora bien, el artículo 106 de la ley № 1123 de 2007 establece que: "si agotada la fase probatoria, el funcionario advierte la necesidad de variar los cargos, así lo declarará breve y motivadamente". Lo dicho implica que quien venía siendo procesado por unas determinadas faltas disciplinarias puede, luego de practicadas las pruebas en el juicio oral, verse expuesto a una nueva imputación que por supuesto significa una valoración distinta de la conducta investigada. Variar los cargos es, pues, renunciar a la imputación inicial para realizar una nueva.

Tal posibilidad lleva a cuestionarse acerca de la vulneración del principio bajo estudio, en el entendido de que las distintas etapas procesales son preclusivas, y que al momento de proferir cargos el funcionario descartó la posible comisión de las faltas no imputadas. No obstante, al responder la pregunta correspondiente, se impone reconocer que la hipótesis planteada no está llamada a prosperar, por cuanto la calificación realizada al momento de formular cargos es de naturaleza provisional, tanto que en ella se mantiene aún la presunción de inocencia del acusado, luego no tiene la fuerza vinculante exigida en el artículo $9^{\circ}$ para que opere el principio del non bis in idem.

77 Santamaría Pastor (2004), p. 214. 


\subsection{La reincidencia}

Esta figura consiste en la repetición de una conducta infractora por parte de una misma persona. La Corte Constitucional en la sentencia C-077/2006 la ha definido como: " una especie de las circunstancias modificativas agravantes de responsabilidad, prevista en algunos ordenamientos penales y, más ampliamente, en algunos ordenamientos sancionatorios, en virtud de la cual se agrava la sanción impuesta al infractor cuando ha sido sancionado anteriormente por la comisión de otras infracciones".

Es por ello que la reincidencia queda por fuera del círculo propio del non bis in idem, pues no se considera que sea el mismo hecho, aunque se trata de la misma persona que vulnera la misma disposición jurídica. En este caso, lejos de proteger al individuo de una doble sanción, se sanciona al individuo que osa violar el ordenamiento en varias ocasiones. Por ende, a pesar de que se trate del mismo sujeto e idéntico bien jurídico, lo correspondiente a la identidad fáctica no concurre en esta ocasión ${ }^{78}$.

\section{Conclusiones}

Tras haber analizado el principio del non bis in idem en el derecho disciplinario abogadil se concluye que:

Entre los principios que orientan la actividad estatal, se destaca el debido proceso y dentro de él el non bis in idem por cuanto persigue la no reiteración del ius puniendi del Estado.

El panorama del principio en estudio en el derecho disciplinario abogadil no es muy claro en Colombia, pues, pese a su consagración constitucional y en instrumentos internacionales, el legislador nacional no ha mostrado interés en desarrollarlo, limitándose exclusivamente a incluirlo como principio rector de los ordenamientos que regulan las distintas modalidades del ius puniendi sin proceder a su reglamentación.

Jurisprudencial y doctrinalmente se ha intentado dar alcance al principio y definir los elementos que lo integran, no obstante, el desarrollo sobre la materia ha sido pobre, siendo el tema de la doble calidad que puede tener un abogado, la que ha Ilamado más la atención de la doctrina científica, aun cuando las decisiones de la Corte siempre se han mantenido en el mismo sentido, en el entendido de autorizar la doble sanción.

\footnotetext{
${ }_{78}$ Sentencia del Consejo de Estado, de 10 de marzo de 2005, Consejera ponente: María Claudia Rojas Lasso, número de radicación: Radicación número: 25000-23-24-000-2002-00689-01, de sección primera. "En efecto, como se infiere de los actos acusados la conducta objeto de las sanciones impuestas por éstos se realizó con varios objetos o productos y en diferentes oportunidades, lo cual, como lo adujo el a quo, justificaba una investigación para cada una de ellas; y, por ende, su correspondiente sanción".
} 
La exigencia de la identidad de bien jurídico posibilita la reiteración de la potestad punitiva del Estado, pues un mismo hecho ontológicamente considerado puede ser valorado, por ejemplo, desde la perspectiva del derecho penal y del derecho disciplinario.

En torno a la identidad objetiva como elemento del principio del non bis in idem, la jurisprudencia colombiana se ha inclinado más por la aceptación de la versión jurídica de los hechos. De este modo, las conductas continuadas y las conductas mediales no pueden ser sancionadas de manera independiente, pues se pondría en peligro el principio.

Al interior del derecho disciplinario abogadil pueden presentarse situaciones que facilitan la vulneración del principio del non bis in idem, tales como: la existencia de decisiones inhibitorias que no adquieren la fuerza de cosa juzgada.

\section{BiBLIOGRAFÍA CITADA}

Barrera NúÑez, Miguel Ángel (2008): Código Disciplinario del Abogado: Comentado por uno de sus redactores (Bogotá, Ediciones Doctrina y Ley Ltda.).

Bermejo Vera, José (2001): Derecho Administrativo, parte especial (Madrid, Civitas).

Betancor Rodríguez, A. (2001): Instituciones de Derecho Ambiental (Madrid, La Ley).

Bula Romero, Jairo Enrique (2006): Derecho Disciplinario: ley No 734 de 2002, (código disciplinario único) ley No 836 de 2003 (Código Disciplinario de las FF.MM.): práctica forense disciplinaria, segunda edición (Bogotá, Temis).

Burgos Martínez, Jaime, Gaitán Peña, Jorge Eliecer; Fernández Arias, Lizardo Rafael (2011): "Existencia de la Relación Especial de Sujeción y su prevalencia para determinar la competencia disciplinaria cuando el abogado desempeña funciones públicas. Inconstitucionalidad del inciso $2^{\circ}$ del artículo 19 de la ley № 1123 de 2007", en: Lecciones de Derecho Disciplinario (Bogotá, Instituto Colombiano de Derecho Disciplinario), pp. 43-72.

Cano Campos, Tomás (2001): "Non bis in ídem, prevalencia de la vía penal y teoría de los concursos en el Derecho Administrativo sancionador", en: Revista de Administración Pública (156), pp. 191-249.

Delgado Rodríguez, María del Pilar (1997): Responsabilidad Profesional del Abogado y Sanciones: jurisprudencia del Consejo Superior de la Judicatura (Bogotá, Dintel).

Díaz Brieva, Álvaro (2007): "El nuevo Código Ético de los Abogados Litigantes Algunos comentarios a la ley No 1123 de 2007", en: Lecciones de Derecho Disciplinario (Bogotá, Instituto de Estudios del Ministerio Público), v. 3. 
FeRNÁNDEZ Cruz, José Ángel (1998): “La naturaleza y contenido del mandato de lex certa en la doctrina del tribunal constitucional español", en: Revista de Derecho (v. 9, n. 1).

Gómez Pavajeau, Carlos Arturo (2007): La Relación Especial de Sujeción (Bogotá, Universidad Externado de Colombia).

Gómez Pavajeau, Carlos Arturo (2004): Dogmática del Derecho Disciplinario (Bogotá, Universidad Externado de Colombia).

Gómez Pavajeau, Carlos Arturo (2009): "La Novedosa pero Aporética jurisprudencia Disciplinaria sobre non bis in idem", en: Problemas Centrales del Derecho Disciplinario, Colección de Derecho Disciplinario (Bogotá, Instituto Colombiano de Derecho Disciplinario y Ediciones Nueva Jurídica).

Huergo Lora, A. (2007): Las sanciones administrativas (Madrid, lustel).

Isaza Serrano, Carlos Mario (2009): Teoría General del Derecho Disciplinario, Aspectos Históricos, Sustanciales y Procesales (Bogotá, Temis).

JesCheCK, H. (1981): Tratado de Derecho Penal (Barcelona, Bosch).

LEÓN VILLALBA, F. (1998): Acumulación de sanciones penales y administrativas (Barcelona, Bosch).

López Barja De Quiroga, Jacobo (20047): El principio: non bis in idem (Dikinson, 2004).

Lopez Nieto y Mallo, Francisco (2002): Las Sanciones Municipales (Madrid, El Consultor).

LozAno CutANDA, (1990): La extinción de las sanciones administrativas y tributarias (Madrid, Marcial Pons).

Monroy Cabra, Marco Gerardo (2002): Ética de Abogado, Régimen Legal y Disciplinario (Bogotá, Ediciones Librería del Profesional).

Nieto García, Alejandro (2007): Derecho Administrativo Sancionador (Madrid, Tecnos).

Nisimblat, Nattan (2009): "La cosa juzgada en la jurisprudencia constitucional colombiana y el principio del estoppel en el derecho anglosajón", en: Vniversitas (118), pp. 247-271.

Ossa Arbeláez, Jaime (2000): Derecho Administrativo Sancionador. Hacia una teoría general y una aproximación para su autonomía (Bogotá, Legis Editores).

RAmírez ToRRADO, María Lourdes (2010): "El criterio de interpretación del principio non bis in idem previsto en el artículo 45.3 de la constitución española", en: lus et Praxis (Año 16, No 1), pp. 287-302.

Ramírez Torrado, María Lourdes (2013): "El non bis in idem en el ámbito administrativo sancionador", en: Revista de Derecho (40), pp. 1-29.

Restrepo Méndez, Luis Enrique (2008): Comentarios al nuevo código disciplinario del abogado (Medellín, Dike). 
Reyes Cuartas, José Fernando (2003): Dos Estudios de Derecho Sancionador Estatal (Bogotá, Instituto de Estudios del Ministerio Público).

Roa Salguero, David Alfonso (2009). "Flexibilización del non bis in idem en materia disciplinaria administrativa y jurisdiccional", en: Lecciones de Derecho Disciplinario (Bogotá, Procuraduría General de la Nación, Instituto de Estudios del Ministerio Público), v. 3.

Romero Rodrícuez, Sophia (2013): "Concurso de normas y concurso de acciones en el derecho procesal civil chileno", en: lus et Praxis (Año 19, № 2), pp. 207-250.

Sánchez Herrera, Esiquio Manuel (2005): Dogmática Practicable del Derecho Disciplinario, Preguntas y Respuestas (Bogotá, Ibáñez).

Santamaría Pastor, Juan Alfonso (2004): Principios de Derecho Administrativo General (Madrid, lustel).

\section{JURISPRUDENCIA CITADA}

Corte Constitucional de Colombia, Sentencia T-145 del 21 de abril, de 1193, Magistrado ponente: Eduardo Cifuentes Muñoz.

Corte Constitucional de Colombia, Sentencia T-413 del 5 de junio de 1992, Magistrado ponente: Ciro Angarita Barón

Corte Constitucional de Colombia, Sentencia T-520 del 16 de septiembre de 1993, Magistrado ponente: José Gregorio Hernández Galindo.

Corte Constitucional de Colombia, Sentencia C-540 del 24 de noviembre, de 1993, Magistrado ponente: Antonio Barrera Carbonell.

Corte Constitucional de Colombia, Sentencia C-319 del 14 de julio de 1994, Magistrado ponente: Hernando Herrera Vergara.

Corte Constitucional de Colombia, Sentencia C-214 del 28 de abril de 1994, Magistrado ponente: Antonio Barrera Carbonell.

Corte Constitucional de Colombia, Sentencia C-259 del 15 de junio de 1995, Magistrado ponente: Hernando Herrera Vergara.

Corte Constitucional de Colombia, Sentencia C-406 del 11 de septiembre de 1995, Magistrado ponente: Fabio Morón Díaz.

Corte Constitucional de Colombia, Sentencia T-652 del 27 de noviembre de 1996, Magistrado ponente: Carlos Gaviria Díaz.

Corte Constitucional de Colombia, Sentencia C-092 del 26 de febrero de 1997, Magistrado ponente: Carlos Gaviria Díaz.

Corte Constitucional de Colombia, Sentencia T-525 del 16 de octubre de 1997, Magistrado ponente: Hernando Herrera Vergara.

Corte Constitucional de Colombia, Sentencia T-162/1998 del de 30 de abril, 1998, Magistrado ponente: Eduardo Cifuentes Muñoz. 
Corte Constitucional de Colombia, Sentencia C-189 del 6 de mayo de 1998, Magistrado ponente: Alejandro Martínez Caballero.

Corte Constitucional de Colombia, Sentencia C-622 del 4 de noviembre 1998, Magistrado ponente: Fabio Morón Díaz.

Corte Constitucional de Colombia, Sentencia C-357 del 19 de mayo 1999, Magistrado ponente: José Gregorio Hernández.

Corte Constitucional de Colombia, Sentencia C-661 del 8 de junio de 2000, Magistrado ponente: Álvaro Tafur Galvis.

Corte Constitucional de Colombia, Sentencia C-333 del 29 de marzo, de 2001, Magistrado ponente: Rodrigo Escobar Gil.

Corte Constitucional de Colombia, Sentencia C-620 del 13 de junio de 2001, Magistrado ponente: Jaime Araujo Rentería.

Corte Constitucional de Colombia, Sentencia C-088 del 13 de febrero de 2002, Magistrado ponente: Eduardo Montealegre Lynett.

Corte Constitucional de Colombia, Sentencia C-181 del 12 de marzo de 2002, Magistrado ponente: Marco Gerardo Monroy Cabra.

Corte Constitucional de Colombia, Sentencia C-391 del 22 de mayo de 2002, Magistrado ponente: Jaime Córdoba Triviño.

Corte Constitucional de Colombia, Sentencia C-233 del 4 de abril 2002, Magistrado ponente: Álvaro Tafur Galvis.

Corte Constitucional de Colombia, Sentencia T-408 del 23 de mayo de 2002, Magistrado ponente: Clara Inés Vargas Hernández.

Corte Constitucional de Colombia, Sentencia C-870 del 15 de octubre de 2002, Magistrado ponente: Manuel José Cepeda Espinosa.

Consejo de Estado, de 22 de noviembre de 2002, consejero ponente: Gabriel Eduardo Mendoza Martelo, Número de radicación: 11001-03-24-000-20010029-01(6770), sección primera.

Corte Constitucional de Colombia, Sentencia C-526 del 3 de julio de 2003, Magistrado ponente: Alfredo Beltrán Sierra.

Corte Constitucional de Colombia, Sentencia C-018 del 20 de enero de 2004, Magistrado ponente: Manuel José Cepeda Espinosa.

Corte Constitucional de Colombia, Sentencia C-194 del 2 de marzo de 2005, Magistrado ponente: Marco Gerardo Monroy Cabra.

Consejo de Estado, de 10 de marzo de 2005, Consejera ponente: María Claudia Rojas Lasso, número de radicación: Radicación número: 25000-23-24-0002002-00689-01, de sección primera.

Corte Constitucional de Colombia, Sentencia T-936 del 8 de septiembre de 2005, Magistrado ponente: Álvaro Tafur Galvis. 
Corte Constitucional de Colombia, Sentencia C-1002 del 3 de octubre de 2005, Magistrado ponente: Marco Gerardo Monroy Cabra.

Corte Constitucional de Colombia, Sentencia T-1110 del 28 de octubre 2005, Magistrado ponente: Humberto Antonio Sierra Porto.

Corte Constitucional de Colombia, Sentencia T-1216 del 24 de noviembre de 2005, Magistrado ponente: Humberto Antonio Sierra Porto.

Corte Constitucional de Colombia, Sentencia C-028 del 26 de enero de 2006, Magistrado ponente: Humberto Antonio Sierra Porto.

Corte Constitucional de Colombia, Sentencia C-077 del 8 de febrero de 2006, Magistrado ponente: Jaime Araujo Rentaría.

Corte Constitucional de Colombia, Sentencia C-393 del 24 de mayo de 2006, Magistrado ponente: Rodrigo Escobar Gil.

Corte Constitucional de Colombia, Sentencia C-471 del 14 de junio de 2006, Magistrado ponente: Álvaro Tafur Galvis.

Corte Constitucional de Colombia, Sentencia C-478 del 13 de junio de 2007, Magistrado ponente: Rodrigo Escobar Gil.

Corte Constitucional de Colombia, Sentencia C-664 del 29 de agosto de 2007, Magistrado ponente: Humberto Antonio Sierra Porto.

Corte Constitucional de Colombia, Sentencia T-971 del 9 de octubre de 2008, Magistrado ponente: Clara Inés Vargas Hernández.

Corte Constitucional de Colombia, Sentencia T-161 del 16 de marzo de 2009, Magistrado ponente: Mauricio González Cuervo.

Corte Constitucional de Colombia, Sentencia C-762 del 29 de octubre de 2009, Magistrado ponente: Juan Carlos Henao Perez.

Corte Constitucional de Colombia, Sentencia C-011 del 20 de enero de 2010, Magistrado ponente: Juan Carlos Henao Pérez.

Corte Constitucional de Colombia, C-899/2011 del 30 de noviembre, Magistrado ponente: Jorge Pretelt Chaljub.

Consejo Superior de la Judicatura la Sala Disciplinaria en providencia del 13 de enero de 2011, proferida con ponencia del Jorge Armando Otálora Gómez, dentro del radicado No. 70001110200020070026401.

Consejo Superior de la Judicatura la Sala Disciplinaria en providencia del once (11) de mayo de dos mil once (2011), proferida con ponencia de: Pedro Alonso Sanabria Buitrago dentro del radicado 17001110200020100029701. Corte Constitucional de Colombia, SU-399/2012, del 31 de mayo, Magistrado ponente: Humberto Sierra Porto. 